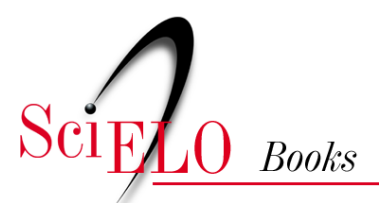

\title{
2. O Símbolo da Medicina
}

\author{
Joffre Marcondes de Rezende
}

\section{SciELO Books / SciELO Livros / SciELO Libros}

REZENDE, J. M. O Símbolo da Medicina. In: À sombra do plátano: crônicas de história da medicina [online]. São Paulo: Editora Unifesp, 2009, pp. 19-30. História da Medicina series, vol. 2. ISBN 978-85-61673-63-5. https://doi.org/10.7476/9788561673635.0003.

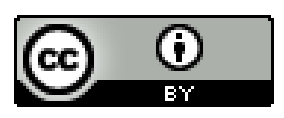

All the contents of this work, except where otherwise noted, is licensed under a Creative Commons Attribution 4.0 International license.

Todo o conteúdo deste trabalho, exceto quando houver ressalva, é publicado sob a licença Creative Commons Atribição 4.0.

Todo el contenido de esta obra, excepto donde se indique lo contrario, está bajo licencia de la licencia Creative Commons Reconocimento 4.0. 


\section{O Símbolo da Medicina*}

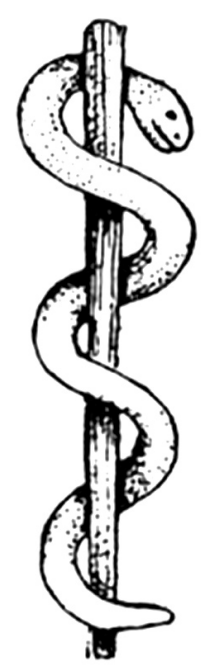

Bastão de Asclépio.

símbolo tradicional da medicina consiste em um bastão com uma serpente em volta. Representa o deus da medicina da civilização grega clássica, Asclépio. Em todas as esculturas e representações, recuperadas nas escavações arqueológicas ou preservadas nas ruínas dos templos a ele dedicados, o deus está segurando em uma de suas mãos um bastão com a serpente. O simbolismo do bastão e da serpente tem dividido as opiniões dos historiadores da medicina. As seguintes interpretações têm sido admitidas:

- Em relação ao bastão: árvore da vida, com o seu ciclo de morte e renascimento; símbolo do poder, como o cetro dos reis e o báculo dos bispos; símbolo da magia, como a vara de Moisés; apoio para as caminhadas, como o cajado dos pastores.

- Em relação à serpente: símbolo do Bem e do Mal, portanto da saúde e da doença; símbolo da astúcia e da sagacidade; símbolo do poder de

* Conferência de abertura do IV Congresso Brasileiro de História da Medicina, São Paulo, I7 dez. I999. 
rejuvenescimento, pela troca periódica da pele; ser ctônico, elo entre o mundo visível e o invisível.

Na mitologia grega, Asclépio é filho de Apolo e da ninfa Coronis, portanto de um deus com uma mortal. Segundo a lenda, Coronis foi-lhe infiel, desposando um pastor. Enciumado, Apolo solicitou à sua irmã Artemis que lhe desfechasse uma seta mortal. Lembrou-se, depois, que Coronis estava grávida de um filho seu e providenciou para que a criança fosse salva por operação cesariana post-mortem. A criança foi entregue ao centauro Quiron, que a criou e ensinou-lhe o uso de plantas medicinais. Asclépio tornou-se um médico famoso que, além de curar os doentes que o procuravam, chegou a ressuscitar um enfermo de nome Hipólito, ultrapassando os limites da medicina. Foi por isso fulminado com um raio por Zeus. Após sua morte, foi cultuado como deus da medicina, tanto na Grécia como no Império Romano, onde passou a chamar-se Esculápio.

Tardiamente, um outro símbolo passou a competir com o bastão de Asclépio. Trata-se do caduceu de Hermes, representado por uma haste central, com duas serpentes dispostas em espirais ascendentes, simétricas e opostas, e com duas asas na sua extremidade superior.

Caduceu, em latim, é a tradução do grego kherykeion, bastão que Hermes teria recebido de Apolo e que servia de salvo-conduto para os arautos, conferindo proteção ao seu portador. $\mathrm{O}$ primitivo caduceu não tinha asas na extremidade superior, as quais foram acrescentadas posteriormente (Friedlander, I992; Muñoz, I98 I, pp. 35-40).

Hermes, na mitologia grega, é o deus do comércio, dos viajantes e das estradas, considerado um deus desonesto, trapaceiro, astuto e mentiroso, deidade do lucro e protetor dos ladrões. Tinha a capacidade de deslocar-se com a velocidade do pensamento e por isso tornou-se o mensageiro dos deuses do Olimpo. Outra de suas atribuições era a de transportar os mortos à sua morada subterrânea, o Hades (Brandão, I988; Chevalier e Gheerbrant, I989; Encyclopaedia Brittannica, I961; Hamilton, I983; Haubrich, I997).

Os romanos deram-lhe o nome de Mercúrio, de merx, que quer dizer mercadoria, negócio. O metal hydrárgyros dos gregos passou a chamar-se mercúrio por sua mobillidade, que o torna de difícil preensão (Hamilton, I983; Haubrich, I997), e o planeta Mercúrio foi assim chamado por ser o mais veloz do nosso sistema planetário. 
O caduceu de Hermes é, de longa data, o símbolo do comércio, sendo por isso utilizado em emblemas de associações comerciais, escolas de comércio e escritórios de contabilidade.

Surge, então, a questão principal do tema que estamos abordando. Por que o símbolo do deus do comércio passou a ser usado também como símbolo da medicina?

Mais de um fato histórico contribuiu para que tal ocorresse.

I. No intercâmbio da civilização grega com a egípcia, o deus Thoth da mitologia egípcia foi assimilado a Hermes e, desse sincretismo, resultou a denominação de Hermes egípcio ou Hermes Trismegistus (três vezes grande), dada ao deus Thoth, considerado o deus do conhecimento, da palavra e da magia (Edelstein e Edelstein, I993). No panteão egípcio, o deus da medicina correspondente a Asclépio é Imhotep e não Thoth (Major, I954).

2. Entre o século III a.C. e o século III d.C. desenvolveu-se uma literatura esotérica chamada hermética, em alusão a HermesTrismegistus. Esta literatura versa sobre ciências ocultas, astrologia e alquimia, e não tem qualquer relação com o Hermes tradicional da mitologia grega. O sincretismo entre o Hermes da mitologia grega e o Hermes Trismegistus resultou no emprego do caduceu como símbolo deste último, tendo sido adotado como símbolo da alquimia. Segundo Schouten, da alquimia o caduceu teria passado para a farmácia e desta para a medicina (Schouten, I967).

3. Um terceiro fato a que se atribui a confusão entre o bastão de Asclépio e o caduceu de Hermes se deve à iniciativa de um editor suíço de grande prestígio, Johan Froebe, no século Xvi, ter adotado para a sua editora um logotipo semelhante ao caduceu de Hermes e o ter utilizado no frontispício de obras clássicas de medicina, como as de Hipócrates e Aetius de Amida. Outros editores na Inglaterra e, posteriormente, nos Estados Unidos, utilizaram emblemas similares, contribuindo para a difusão do caduceu (Friedlander, I992).

Admite-se que a intenção dos editores tenha sido a de usar um símbolo identificado com a transmissão de mensagens, já que Hermes era o mensageiro do Olimpo. Com a invenção da imprensa por Gutenberg, a informação passou a ser transmitida por meio da palavra impressa, e eles, os editores, seriam os mensageiros dos autores. Outra hipótese é de que o caduceu tenha sido usado equivocadamente como símbolo de Hermes Trimegistus, o Hermes egípcio ou Thoth, deus da palavra e do conhecimen- 
to, a quem também se atribuía a invenção da escrita. Em antigas prensas utilizadas para impressão tipográfica encontra-se o caduceu de Hermes como figura decorativa.

4. Outro fato que certamente colaborou para estabelecer a confusão entre os dois símbolos é o de se conferir o mesmo nome de caduceu ao bastão de Asclépio, criando-se uma nomenclatura binária de caduceu comercial e caduceu médico. Este erro vem desde o século XIX e persiste até os dias de hoje.

Em I90I, o exército francês fundou um jornal de cirurgia e de medicina chamado Le caducée, no qual estão estampadas duas figuras estilizadas do símbolo de Asclépio, com uma única serpente (Friedlander, I992).

Desde então, a palavra caduceu tem sido usada para nomear tanto o símbolo de Hermes como o bastão de Asclépio.

5. O fato que mais contribuiu para a difusão do caduceu de Hermes como símbolo da medicina foi a sua adoção pelo Exército norte-americano como insígnia do seu departamento médico. As justificativas e argumentos para essa adoção são falhas, inconsistentes, e denotam, no mínimo, desconhecimento da iconografia mitológica por parte dos que detinham o poder para promover a mudança. As informações que se seguem sobre este episódio foram colhidas em grande parte no livro de Walter Friedlander, The Golden Wand of Medicine.

O caduceu fora usado, entre i 85 I e I 887, como emblema no uniforme de trabalho do pessoal de apoio nos hospitais militares dos Estados Unidos para indicar a condição de não-combatente. Em I 887 este emblema foi substituído por uma cruz vermelha idêntica a da Cruz Vermelha Internacional, fundada na Suíça em I 864. Os oficiais médicos usavam nas dragonas as letras M. S. (Medical Staff).Em I 872, as letras M. S. foram substituídas por M. D. (Medical Department). O Departamento Médico, contudo, possuía o seu próprio brasão de armas com o bastão de Asclépio, desde I8 8 8 (Chevalier e Gheerbrant, I989).

Em março de 1902, os oficiais médicos passaram a usar um emblema inspirado na cruz dos cavaleiros de São João, ou cruz de Malta, cujo simbolismo em heráldica é o de proteção, altruísmo e honorabilidade.

Em 20 de março de 1902, o capitão Frederick P. Reynolds, comandante da Companhia de Instrução do Hospital Geral em Washington propôs substituir a cruz de Malta pelo caduceu.

O general G. Sternberg, chefe do Departamento Médico, deu o seguinte despacho: "A atual insígnia foi adotada após cuidadoso estudo e é atual- 
mente reconhecida como própria desta corporação. A alteração proposta, portanto, não é aprovada”.

Em I4 de junho do mesmo ano, o capitão Reynolds endereçou nova carta ao chefe do Departamento, refazendo sua proposta com novos argumentos. Em certo trecho de sua carta diz o seguinte:

Desejo particularmente chamar a atenção para a conveniência de mudar a insígnia da cruz para o caduceu e de adotar o marrom como a cor da corporação, em lugar do verde agora em uso. O caduceu foi durante anos a insígnia de nossa corporação e está inalienavelmente associado às coisas médicas. Está sendo usado por várias potências estrangeiras, especialmente a Inglaterra. Como figura, deve-se reconhecer que o caduceu é muito mais gracioso e significativo do que o atual emblema (cruz de Malta). $\mathrm{O}$ verde não tem lugar na medicina.

Nesse ínterim, houve mudança na chefia do Departamento Médico e esta segunda carta foi recebida pelo general William Henry Forwood, que não somente aprovou a proposta, como providenciou a confecção da nova insígnia. $\mathrm{O}$ desenho elaborado tem sete curvaturas das serpentes, o que também revela desconhecimento do caduceu tradicional, que contém, no máximo, cinco espirais.

Os argumentos usados pelo capitão Reynolds revelam sua confusão entre os dois símbolos. O caduceu jamais fora a insígnia da corporação, mas do pessoal de apoio (steward) dos hospitais. O bastão de Asclépio e não o caduceu é que está historicamente associado à medicina. Tanto na Inglaterra, como na França e na Alemanha, os serviços médicos das forças armadas utilizavam o bastão de Asclépio em seus emblemas e não o caduceu de Hermes.

Finalmente, a cor verde tem sido usada em conexão com a medicina, tanto assim que no Brasil o anel de médico tem, incrustada, uma pedra verde - esmeralda ou imitação.

$\mathrm{O}$ argumento de ordem subjetiva de que a figura do caduceu tem estética mais agradável que a cruz de Malta ou o bastão de Asclépio é irrelevante, porquanto não diz respeito ao significado de tais símbolos.

Deste modo, o caduceu foi implantado e se mantém até hoje como insígnia do Corpo Médico do Exército norte-americano, o que muito 


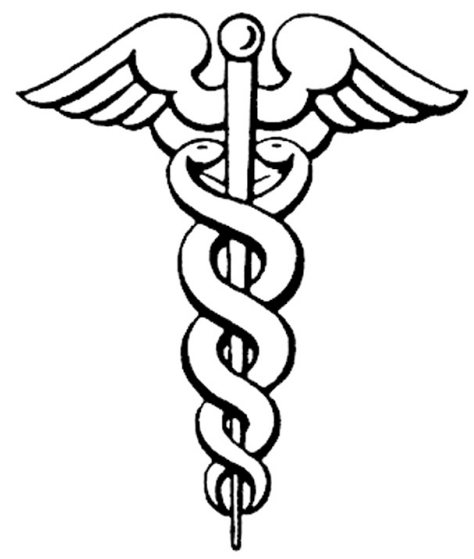

Caduceu de Hermes.

contribuiu, sobretudo após a Primeira Guerra Mundial (I9I4-I9I8), para a sua difusão, dentro e fora dos Estados Unidos, como símbolo da medicina (Friedlander, I992).

A Marinha norte-americana adotou igualmente o caduceu como emblema de seu corpo médico, ao contrário da Força Aérea, que mantém em seu emblema o bastão de Asclépio.

Os Serviços de Saúde Pública dos Estados Unidos, por sua vez, adotaram um antigo emblema do Serviço Médico da Marinha, no qual o caduceu se cruza com uma âncora e cujo simbolismo anterior era o do comércio marítimo.

O primeiro comentário desfavorável à decisão do Departamento Médico norte-americano apareceu sob a forma de editorial em final de julho de 1902 na publicação Medical News. Desde então, de tempos em tempos, surgem artigos na imprensa médica, ora justificando, ora condenando o uso do caduceu como símbolo da medicina.

Em I9I7, o tenente-coronel McCulloch, bibliotecário do Departamento Médico, fez o seguinte comentário: "Eu penso que, neste país, nós prestamos muito pouca atenção ao lado histórico e humanístico das coisas. O caduceu de Mercúrio agora em uso na gola da blusa do uniforme do Corpo Médico não tem qualquer significado médico" (McCulloch Jr., I9I7, pp. I37-I48).

Fielding Garrison, notável historiador da medicina nos Estados Unidos e também tenente-coronel do Corpo Médico no período de I9I7 a I935, 
procurou defender a posteriori a adoção do caduceu pelo Departamento Médico a que servia. Inicialmente, alegou que se tratava de um símbolo administrativo para caracterizar os militares não combatentes, reconhecendo que o símbolo autêntico da medicina era o bastão de Asclépio. Posteriormente, procurou justificar o uso do caduceu como símbolo médico com base nos achados arqueológicos da civilização mesopotâmica.

Nas escavações realizadas em Lagash fora encontrado um vaso talhado em pedra sabão, de cor verde, dedicado pelo governador Gudea ao deus Niginshzida, ligado à medicina. Neste vaso há duas serpentes dispostas de maneira semelhante a do caduceu de Hermes. Garrison refere-se à figura como caduceu babilônico, que teria precedido o caduceu da civilização grega (Garrison, I919, pp. 633-636).

A verdade é que toda a cultura médica ocidental baseia-se na civilização grega. Todos os aspectos conceituais, técnicos e éticos da profissão médica, tiveram seu berço na Grécia com a escola hipocrática. Foi na Grécia que a medicina deixou de ser mágico-sacerdotal para apoiar-se na observação clínica e no raciocínio lógico. O símbolo mítico de Asclépio, o bastão com uma única serpente, representa a medicina grega em suas origens e nenhum outro símbolo, muito menos o caduceu de Hermes, deverá substituí-lo.

Em I932, S. L.Tyson escreveu um artigo na revista Scientific Monthly, no qual dizia: "o errôneo símbolo da profissão médica, é, na realidade, o do deus dos ladrões" (Tyson, I932). Em resposta, Garrison voltou a afirmar que o caduceu fora adotado no Departamento Médico do Exército como símbolo dos não-combatentes e considerou a questão como "uma fútil controvérsia" (Friedlander, I992).

O Army Medical Department acolhe a seguinte explicação para a adoção do caduceu de Hermes como símbolo da medicina: "Com suas raízes na mitologia, o caduceu tem sido historicamente o emblema dos médicos, simbolizando conhecimento, sabedoria, presteza e habilidade" (Internet, 2008).

Parece evidente a confusão entre o Hermes da mitologia grega tradicional e o Hermes Trismegistus, o deus Thoth da mitologia egípcia.

A Associação Médica Americana manteve o símbolo de Asclépio em seu emblema, assim como a maioria das sociedades médicas regionais norte-americanas de caráter científico ou profissional. De 25 associações 
médicas estaduais que utilizam a serpente em seus respectivos emblemas, 23 usam o bastão de Asclépio. São elas as dos estados de Alabama, Califórnia, Flórida, Geórgia, Idaho, Illinois, Kansas, Kentucky, Massachusetts, Michigan, Mississippi, Missouri, Nebraska, New Hampshire, Novo México, Nova York, Dakota do Norte, Oklahoma, Oregon, Pensilvânia, Utah, Wisconsin e Wyoming. O caduceu é usado pelas associações dos estados de Maine e Virgínia Ocidental.

A Organização Mundial de Saúde, fundada em I948, como não poderia deixar de ser, adotou o símbolo de Asclépio. A Associação Médica Mundial, reunida em Havana em I956, adotou um modelo padronizado do símbolo de Asclépio para uso dos médicos civis.

As organizações médicas de caráter profissional e de âmbito nacional de vários países, que possuem emblema com serpente, adotam, em sua grande maioria, o símbolo de Asclépio, a começar pela Associação Médica Americana, já citada. Entre as associações que assim procedem citaremos as do Brasil, Canadá, Costa Rica, Inglaterra, França, Alemanha, Suécia, Dinamarca, Itália, Portugal, África do Sul, Austrália, Nova Zelândia, países do Sudeste Asiático, China e Taiwan.

Sociedades de história da medicina, sociedades científicas de especialidades médicas, faculdades de medicina, revistas médicas e até empresas de seguro-saúde, como a aliança Blue Cross-Blue Shield, utilizam o símbolo de Asclépio.

É óbvio que todo símbolo pode ser estilizado, porém não pode ser substituído por outro. Como estilizações originais do símbolo de Asclépio podemos citar os seguintes exemplos:

- o da Associação Paulista de Medicina e o da Academia Brasileira de Medicina Militar, em que o bastão toma a configuração de uma espada;

- o da Escola Paulista de Medicina, em que o bastão é o próprio tronco de uma árvore;

- o da Sociedade Espanhola de Medicina do Trabalho, em que o bastão assume a forma de uma chave-inglesa como instrumento de trabalho;

- o da Associação Brasileira de Educação Médica, em que o bastão é uma tocha, simbolizando a luz do saber;

- o da Faculdade de Medicina de Ribeirão Preto, em que a serpente assume o formato de um nó cirúrgico. 
Algumas poucas organizações médicas de âmbito nacional utilizam o caduceu de Hermes em seus emblemas, ou em sua forma original, ou modificado, tais como as da Coreia, Hong Kong e ilha de Malta.

O caduceu de Hermes, estilizado, foi também adotado pelo Serviço Médico da Royal Air Force, da Inglaterra, divergindo do Serviço Médico do Exército, que mantém seu clássico emblema com o símbolo de Asclépio desde 1898.

Variantes do caduceu têm sido igualmente utilizadas, resultantes de duas alterações introduzidas no modelo original: a primeira delas consiste em eliminar uma das serpentes, mantendo as asas, tal como nos emblemas da American Gastroenterological Association e da Facoltà di Medicina e Chirurgia, de Florença; a segunda, conservando as duas serpentes e eliminando as asas, como nos emblemas da Società Italiana di Medicina Interna e da Associação Médica da Malásia.

Nos Estados Unidos, onde é mais difundido o caduceu de Hermes como pretenso símbolo da medicina, o mesmo é usado em algumas poucas universidades e sociedades médicas, sendo mais comum o seu emprego em hospitais e instituições públicas e privadas ligadas à saúde.

Segundo um levantamento realizado até i980, o caduceu é usado principalmente pelas empresas que gerenciam planos de saúde naquele país, chegando a $76 \%$ de quantas utilizam a serpente em seus emblemas (Friedlander, 1992).

No dizer de Geelhoed, o caduceu tornou-se um símbolo evocativo da situação atual da medicina, em que os aspectos econômicos e comerciais da saúde se sobrepõem aos aspectos humanos, o que é inaceitável. Para aqueles que desejarem preservar os ideais da tradição médica só há um símbolo verdadeiro, que é o de Asclépio.

Como sugeriu Tyson, o símbolo de Hermes poderia ser usado, no máximo, em carros funerários, já que uma das atribuições de Hermes era a de conduzir os mortos à sua morada subterrânea (Tyson, I932). Fora desse contexto, o caduceu de Hermes, como símbolo médico, é uma heresia.

As críticas desfavoráveis ao seu uso como símbolo da medicina persistem até o presente, como demonstram os comentários a seguir, veiculados, respectivamente, em i988, 1996 e 1999. 


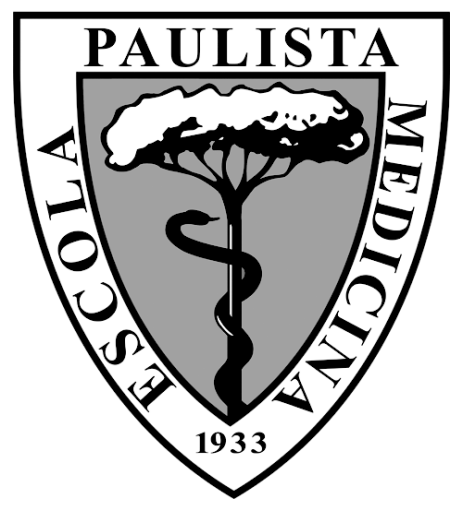

Emblema adotado pela Escola Paulista de Medicina antes de se tornar Universidade Federal de São Paulo.

O caduceu é um usurpador, um retardatário no simbolismo médico e um pretendente de duvidosa legitimidade (Geelhoed, I988, pp. I I 55-I I6I).

A associação dos médicos com o furto, pela adoção do caduceu de Hermes como símbolo da medicina é, sem dúvida, indesejável e somente os cínicos que acusam os médicos de interesse excessivo em ganhar dinheiro podem achá-lo apropriado (Nichols, I996).

O caduceu nada tem a ver com a saúde, o tratamento das doenças ou as artes médicas. $\mathrm{O}$ exército norte-americano, resoluto no erro como todos os exércitos costumam ser, adotaram o caduceu como insígnia do seu Departamento Médico. O poder da influência militar deslocou o bastão de Asclépio de seu lugar mítico (Collins, I999; Garrison, I919).

No Brasil, prevalece no meio médico o símbolo de Asclépio. A Associação Médica Brasileira, assim como as sociedades estaduais a ela filiadas que possuem emblema com a serpente, utilizam o símbolo correto do deus da medicina.

Assistimos, porém, a disseminação do caduceu de Hermes entre nós, através dos meios de comunicação: televisão, jornais, impressos, anúncios, adesivos, desenhos em objetos e utensílios destinados a médicos e estudantes de medicina. Conforme ressaltou o prof. Alcino Lázaro da Silva: “a mídia brasileira, por engano, por falácia, por má-interpretação, por má-informação 
ou por má-fé, passou a usar o símbolo do comércio como ilustração quando se refere a notícias médicas" (Lázaro da Silva, I999, pp. 43-45).

Também os softwares destinados a hospitais e consultórios médicos, importados dos Estados Unidos, ou neles inspirados, muito têm contribuído para a propagação do caduceu, ao utilizá-lo como identificador de sua destinação.

Lamentavelmente, o caduceu como símbolo da medicina já pode ser encontrado em nosso país em revistas e sociedades médicas de fundação mais recente, em sites da internet dedicados à medicina, e até mesmo em impressos de algumas universidades.

Cremos ser necessária uma campanha de esclarecimento, sobretudo nas faculdades de medicina, junto aos estudantes do curso de graduação, no sentido de alertá-los sobre o único e verdadeiro símbolo da medicina: o bastão de Asclépio com uma só serpente. O caduceu de Hermes, símbolo do comércio, deve ser visto como um símbolo impróprio aos nobres ideais da medicina.

\section{Referências Bibliográficas*}

Brandão, J. S. Mitologia Grega. 2aㅡ ed., Petrópolis, Vozes, I988, vol. 2.

Castiglioni, A. Histoire de la médecine. Paris, Payot, I93 I.

Chevalier, J. \& Gheerbrant, A. Dicionário de Símbolos. 2ª ed., Rio de Janeiro, José Olympio, I989.

Collins, S. G. "Comments on the book The Golden Wand of Medicine”. Custer, I 8 mar. I999.

Edelstein, E. J. \& Edelstein, L. Asclepius: Collection and Interpretation of

Testimonies. Baltimore, The Johns Hopkins University Press, I993.

ENCYCLOPAEDIA BRITTANNICA. Chicago, I96I.

Ernout, A. \& Meillet, A. Dictionnaire étymologique de la langue latine: histoire des mots. $4^{\underline{a}}$ ed., Paris, Ed. Klincksieck, I979.

Fons JR., J. W. “The Serpent as a Medical Emblem”. Marquette Medical Review, 26, pp. I3-I 5, I960.

Fowden, G. The Egyptian Hermes. New Jersey, Princeton University Press, I993.

Friedlander, W. J. The Golden Wand of Medicine. Westport, Greenwood Press, I992.

* Das fontes bibliográficas citadas, merece destaque o livro de Walter J. Friedlander, The Golden Wand of Medicine, cuja leitura recomendamos a todos os interessados no assunto. 
Garrison, F. H. “The Babylonian Caduceus”. Military Surgeon, 44, pp. 633-636, I9I9.

Geelhoed, G. W. “The Caduceus as a Medical Emblem: Heritage or Heresy?”. Southern Medical Journal, 8I, pp. I I 55-I I6I, I988.

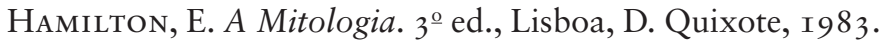

Haubrich, W. S. Medical Meanings: A Glossary of Word Origins. Philadelphia, American College of Physicians, 1997.

INTERnET - Medical corps. Disponivel em http://usmilitary.about.com Acesso em Io out. 2008.

Kerényi, C. Asklepios: Archetypal Image of the Physician's Existence. London, Thames and Hudson, I960.

Lawrence, C. "The Healing Serpent: The Snake in Medical Iconography”. The Ulster Medical Journal, 47, pp. I34-I40, I978.

LÁzaro da Silva, A. “Símbolo da Medicina”. Boletim Informativo do Colégio Brasileiro de Cirurgiões, pp. 43-45, abr.-jun. I999.

Major, R. A. A History of Medicine. Springfield, Charles C. Thomas, I954.

McCulloch JR., C. C. "The Coat of Arms of the Medical Corps". Military Surgeon, 4I, pp. I37-I48, I9I7.

Metzer, W. S. "The Caduceus and the Aesculapian Staff: Ancient Eastern Origins, Evolution and Western Parallels". Southern Medical Journal, 82, pp. 743-748, 1989.

Muñoz, P. "Origins of Caduceus”. Maryland State Medical Journal, pp. 35-40, out. I98 I.

Nichols, D. "Walk Among Gods". Iatros, vol. ıо, n. Io, I996.

Schouten, J. The Rod and Serpent of Asklepios: Symbol of Medicine. Amsterdam, Elsevier Publ. Co., I967.

Tyson, S. L. “The Caduceus”. Scientific Monthly, 34, pp. 492-498, I932.

Williams, N. W. "Serpents, Staffs, and the Emblems of Medicine". JAMA: The Journal of the American Medical Association, 28I, pp. 475-476, I999. 